\title{
Development of $\alpha$-GalCer Analogues with an $\alpha$-Fluorocarbonyl Moiety as Th2-Selective Ligands of CD1d
}

\author{
Hyunsoo Kim, ${ }^{\dagger, \S}$ Heebum Song, ${ }^{\dagger, \S, \|}$ Jun-Gyu Park, ${ }^{\ddagger}$ Dong-Sup Lee, ${ }^{\ddagger}$ and Seung Bum Park ${ }^{*} \dagger^{\dagger}$ \\ ${ }^{\dagger}$ CRI Center for Chemical Proteomics, Department of Chemistry, Seoul National University, Seoul 08826, Korea \\ ${ }^{\ddagger}$ Department of Biomedical Sciences, Seoul National University College of Medicine, Seoul 03080, Korea
}

Supporting Information

ABSTRACT: A series of $\alpha$-GalCer analogues containing an $\alpha$-fluorocarbonyl moiety at the terminal position of the acyl chain were designed for targeting polar residues in the hydrophobic cavity of CD1d using a structure-based approach. The acyl chain length was efficiently adjusted by an asymmetric alkyne-alkyne cross coupling strategy, and the newly synthesized $\alpha$-GalCer analogues showed the high Th2-selective activity of iNKT cells. The biased activity of ligands could be caused by the hydrogen-bonding interaction between ligands and CD1d according to the Th2-selective cytokine secretion and molecular docking studies.

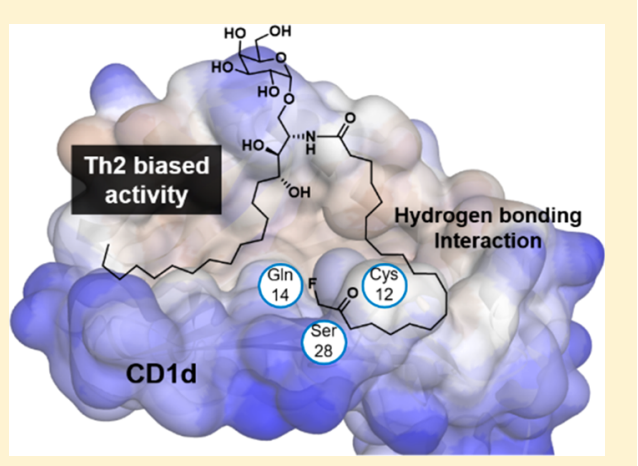

KEYWORDS: $\alpha$-Galactosylceramide, CD1d, hydrogen-bonding interaction, rational design, cytokine secretion

$\mathrm{C}$

D1d is a monomorphic major histocompatibility complex (MHC) class I-like protein expressed on various antigenpresenting cells. ${ }^{1} \mathrm{CD} 1 \mathrm{~d}$ presents lipid antigens to natural killer $\mathrm{T}$ (NKT) cells, which is similar to the MHC protein presenting peptide antigens to conventional $\mathrm{T}$ cells. ${ }^{2}$ NKT cells recognize $\mathrm{CD} 1 \mathrm{~d}$-lipid antigen binary structures through the $\mathrm{T}$ cell receptor (TCR), which triggers the release of various cytokines to regulate immune responses. ${ }^{3}$ The first reported and most extensively studied lipid antigen presented in CD1d is a synthetic glycolipid, $\alpha$-galactosylceramide $(\alpha$-GalCer, also known as KRN7000), which is composed of $\alpha$-linked galactose with a phytosphingosine backbone and saturated $N$-linked fatty acyl chain (Figure 1a). ${ }^{4}$ After the discovery of $\alpha$-GalCer, a series of $\alpha$-GalCer analogues have been designed and synthesized, $^{5-9}$ and the subsequent biological evaluations were conducted to study the NKT cell activation according to the interaction between CD1d and glycolipid ligands. ${ }^{10-12}$ Based on those efforts, a significant amount of understanding about NKT cell biology has been gleaned. But, there are some unanswered questions about the molecular basis of TCR-lipid antigen-CD1d interaction, and studies on these ternary structures are still actively pursued.

The TCR $-\alpha$ GalCer-CD1d ternary complex was defined through X-ray crystallographic studies, and the binding mode of $\alpha$-GalCer within CD1d was well studied. ${ }^{13,14}$ CD1d has two hydrophobic antigen binding grooves, the $\mathrm{A}^{\prime}$ pocket and $\mathrm{F}^{\prime}$ pocket (Figure 1b, upper panel), interacting with the acyl chain and phytosphingosine chain, respectively, and the sugar part of glycolipids protrudes out of the antigen-binding grooves in $\mathrm{CD} 1 \mathrm{~d}$. Although CD1d is a nonpolymorphic structure, it has a large binding pocket, approximately $1650 \AA^{3}$. Thus, diverse glycolipid ligands could occupy the binding pocket of CD1d. ${ }^{15}$ Because the CD1d binding groove mainly interacts with the fatty acid chain, most of the residues existing in the binding grooves have hydrophobic properties, ${ }^{16}$ which indicates that hydrophobic interactions are the critical factor for binding of glycolipid ligands to CD1d. Thus, to date most $\alpha$-GalCer analogues have focused on modulating hydrophobic interactions of ligands and $\mathrm{CD} 1 \mathrm{~d}$. However, there are some polar residues such as Cys12, Gln14, and Ser28 in the $\mathrm{A}^{\prime}$ pocket (Figure 1b, bottom panels), and a few studies utilized those hydrophilic residues for designing $\alpha$-GalCer analogues to change the binding properties between CD1d and lipid antigens. ${ }^{17-19}$ In 2014, Kim and co-workers focused on those polar residues in the $\mathrm{A}^{\prime}$ pocket of $\mathrm{CD} 1 \mathrm{~d}$, designed $\alpha$ GalCer analogues containing the truncated $\omega$-hydroxyl acyl chain (Figure 1a), ${ }^{17}$ and claimed that these analogues retained the NKT cell stimulation activity comparable with the original $\alpha$-GalCer. Recently, Fujimoto and co-workers introduced an amide group in the middle of the acyl chain (Figure 1a) ${ }^{18}$ and demonstrated that the interaction between amide group and hydrophilic residues in the $\mathrm{A}^{\prime}$ pocket induces the Th2-selective response of cytokines in NKT cells. ${ }^{19}$

In this study, we focused our attention on the hydrophilic residues in the $\mathrm{A}^{\prime}$ pocket of $\mathrm{CD} 1 \mathrm{~d}$. Based on the idea that using polar residues in the hydrophobic binding pocket could generate a different interaction, we rationally designed a new series of $\alpha$-GalCer derivatives. Among polar residues, unlike

Received: January 23, 2019

Accepted: April 24, 2019

Published: April 24, 2019 


\section{a}

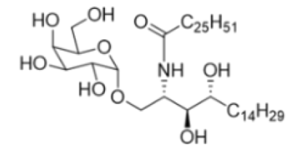

a-Galactosylceramide
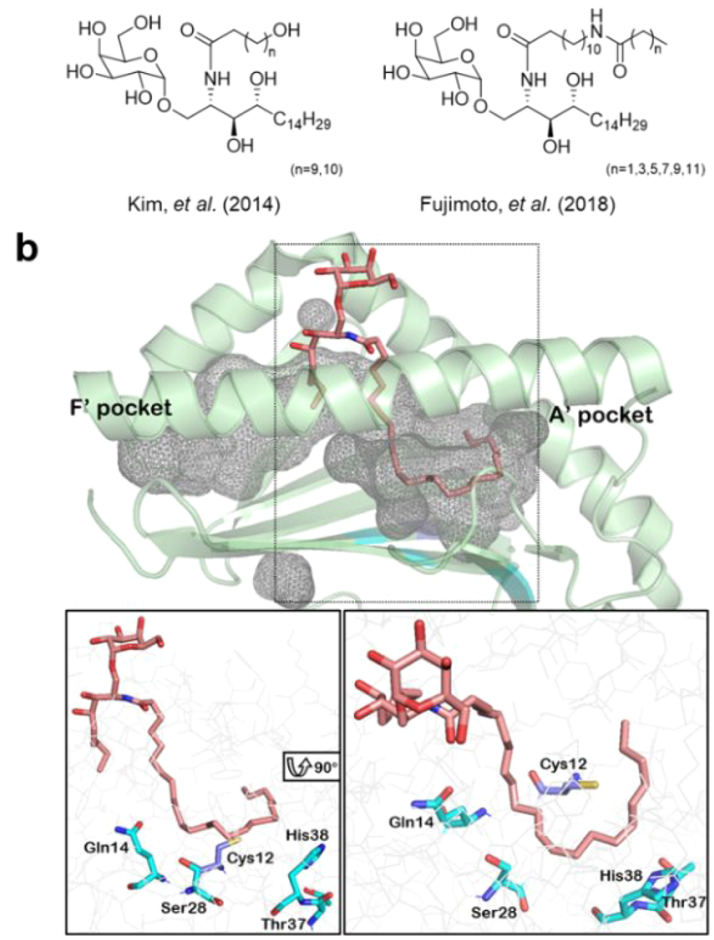

Figure 1. (a) Chemical structures of $\alpha$-GalCer, $\mathrm{OCH}$, and $\alpha$-GalCer analogues targeting polar residues in the $\mathrm{A}^{\prime}$ pocket of $\mathrm{CD} 1 \mathrm{~d}$. (b) Overview of the binding mode of $\alpha$-GalCer analogues and their location of the $\mathrm{A}^{\prime}$ pocket and $\mathrm{F}^{\prime}$ pocket in $\mathrm{mCD} 1 \mathrm{~d}$. The gray mesh indicates a cavity in mCD1d, and the structure of an $\alpha$-GalCer analogue is shown as a pale pink stick. (PDB: 3G08, ligand: $\mathrm{OCH}$ ) The figure in the black box shows hydrophilic residues in the $\mathrm{A}^{\prime}$ pocket. Hydrophilic residues are shown as a stick in cyan color; among them Cys12 is shown in pale purple.

previous studies, we concentrated on the Cys12 residue because cysteine has hydrophilic properties as well as nucleophilicity. ${ }^{20}$ We maintained the original structure of fatty acyl chain as much as possible in order not to interrupt the existing hydrophobic interaction between $\alpha$-GalCer and CD1d. Instead, we introduced a mildly reactive moiety at the terminal site of the acyl chain and tried to induce an additional interaction (Figure 2a). The $\alpha$-fluorocarbonyl moiety was selected as a mildly reactive electrophile to generate potential covalent interactions between ligands and CD1d on the basis of the nucleophilicity of cysteine residue. Previous reports claimed the formation of covalent bonds in CD1d-glycolipid conjugates; ${ }^{21}$ Porcelli and co-workers introduced the photoreactive benzophenone moiety in the acyl chain to make a covalent linkage between CD1d and the ligand upon UV irradiation, which allows the formation of covalent conjugates of CD1d-glycolipids. But there are limitations in its biological application because the benzophenone moiety needs to be activated by external UV irradiation. Therefore, it has no sitespecific reactivity, and this type of activation does not naturally occur under the physiological conditions. On the contrary, the $\alpha$-fluorocarbonyl moiety is known to possess good selectivity a

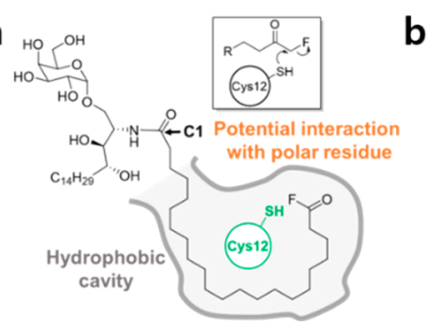

b

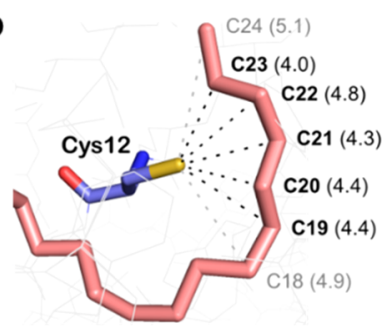

C

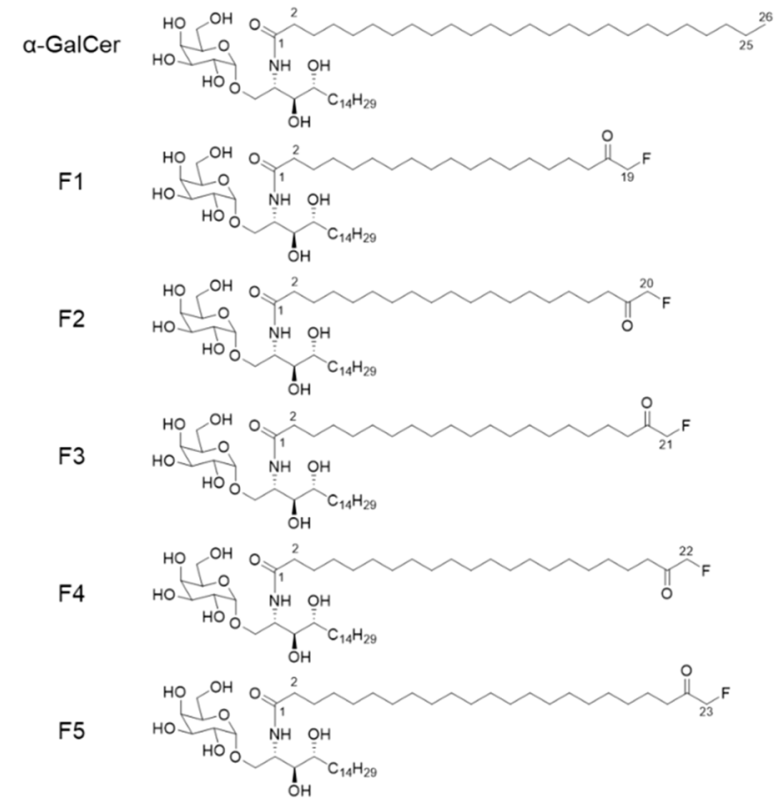

Figure 2. (a) Design of $\alpha$-GalCer analogues with an $\alpha$-fluorocarbonyl moiety at the terminus of the acyl chain. (b) Measurement of the distance between the cysteine sulfur and the carbon atoms on the acyl chain. (c) Structure of the $\alpha$-GalCer analogues F1 to F5.

and reactivity toward the cysteine thiol of proteins under the physiological conditions. ${ }^{2-24}$

At first, we analyzed the high-resolution cocrystal structure of $\mathrm{mCD} 1 \mathrm{~d}-\alpha$-GalCer derivative (PDB: 3G08, resolution: 1.6 $\AA$ ) to obtain the spatial information around Cys12. As shown in Figure $2 \mathrm{~b}$, we measured the distance between cysteine sulfur and carbon atoms $(\mathrm{C} 18-\mathrm{C} 24)$ on the acyl chain, which provided us a clue about the optimal position in which to put the electrophilic $\alpha$-carbon of the $\alpha$-fluorocarbony moiety. We selected five carbon sites whose distances from cysteine sulfur ranged from the minimum of $4.0 \AA$ to the maximum of $4.8 \AA$. Based on this information, we designed five different $\alpha$-GalCer analogues containing the $\alpha$-fluorocarbonyl moiety. The resulting five $\alpha$-GalCer analogues presented in Figure 2c were synthesized as shown in Scheme 1 . Original $\alpha$-GalCer has a fully saturated C-26 length acyl chain, and our designed $\alpha$ GalCer analogues have acyl chains with different chain lengths in the range from $\mathrm{C}-19$ to $\mathrm{C}-23$. For synthesis of the designed analogues, we prepared long fatty acids with five different chain lengths via a modular alkyne-alkyne cross coupling strategy with two medium-length intermediates under CadiotChodkiewicz reaction conditions.

We first synthesized three linear chain alcohols having C-8 to $\mathrm{C}-10$ length with a terminal alkyne. As the coupling partners of the Cadiot-Chodkiewicz reaction, terminal alkynes with a THP-protected hydroxyl group $(\mathbf{1 a}-\mathbf{c})$ and brominated terminal alkynes $(\mathbf{2} \mathbf{a}, \mathbf{2} \mathbf{b})$ were prepared. Then, the terminal 
Scheme 1. Synthesis of $\alpha$-GalCer Analogues F1-F5 ${ }^{a}$

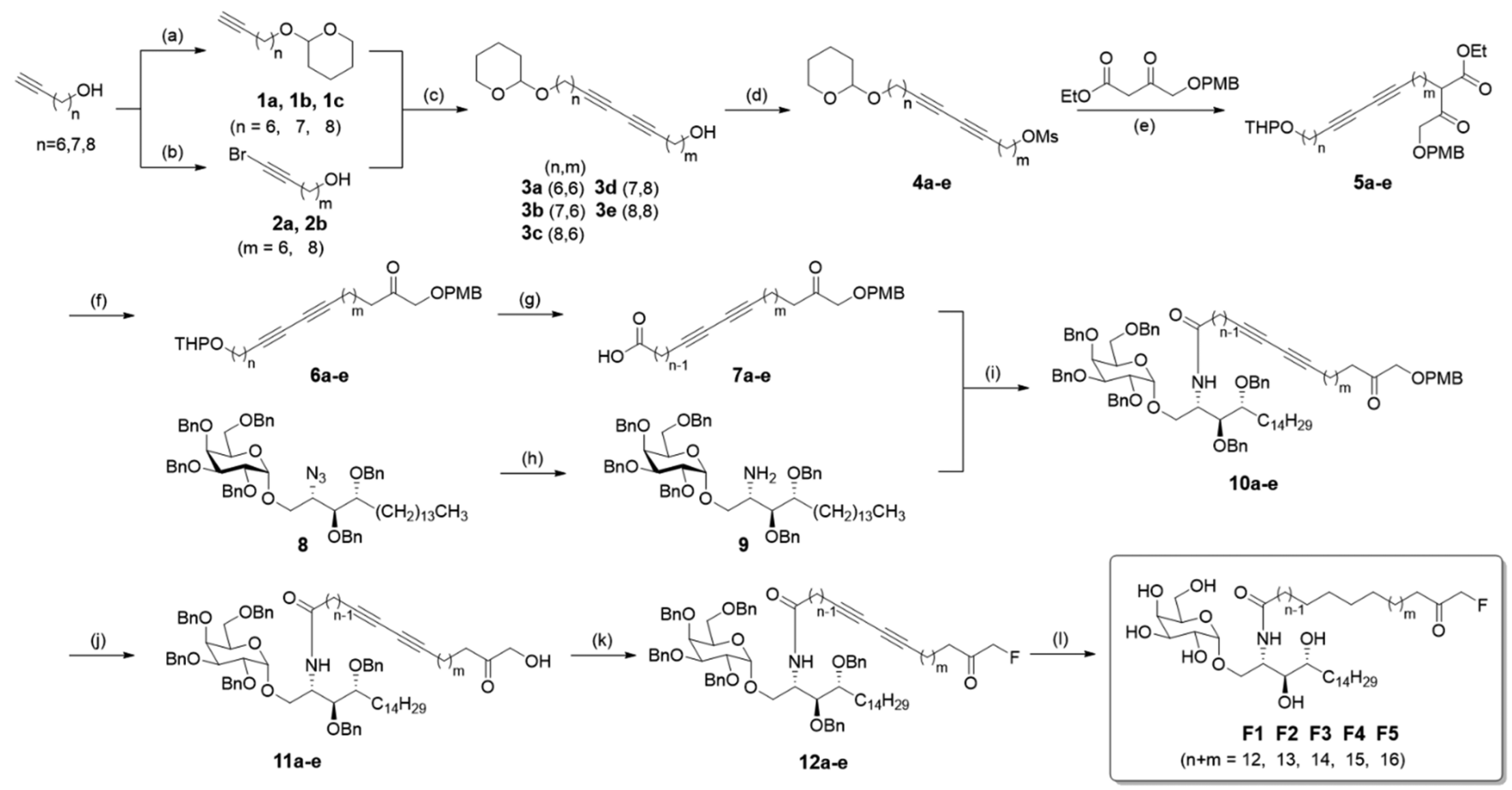

${ }^{a}$ Conditions: (a) 3,4-Dihydropyran, pyridine, $p$-toluenesulfonate (PPTS), dichloromethane (DCM), at room temperature (r.t.) for 3 h, 95-98\%; (b) $\mathrm{N}$-Bromosuccinimide, $\mathrm{AgNO}_{3}$, acetone, r.t., overnight, $91 \%$ (2a) and $87 \%$ (2b); (c) $\mathrm{CuCl}, \mathrm{NH}_{2} \mathrm{OH} \cdot \mathrm{HCl}, 30 \%$ - $\mathrm{BuNH}$ (aq.), r.t., overnight, 43-85\%; (d) MsCl, triethylamine (TEA), tetrahydrofuran (THF), r.t., 3 h, 94-99\%; (e) $\mathrm{K}_{2} \mathrm{CO}_{3}$, $\mathrm{KI}$, acetone/dimethylformamide (DMF) (15:1, v/v), $75{ }^{\circ} \mathrm{C}$, overnight; (f) $10 \% \mathrm{KOH}$ (aq.), $\mathrm{MeOH}, 45{ }^{\circ} \mathrm{C}$, overnight, $51-71 \%$ (2 steps); (g) Jones reagent, acetone, $0{ }^{\circ} \mathrm{C}, 3 \mathrm{~h}$; $(\mathrm{h}) \mathrm{PPh}_{3}$, benzene $/ \mathrm{H}_{2} \mathrm{O}(100: 1, \mathrm{v} / \mathrm{v}), 60^{\circ} \mathrm{C}, 12 \mathrm{~h}$; (i) 1-Ethyl-3-(3-dimethylamino-propyl)carbodiimide (EDC), dimethylaminopyridine (DMAP), THF, r.t., $24 \mathrm{~h}, 31-79 \%$ (2 steps); (j) Trifluoroacetic acid (TFA)/DCM (1:20, v/v), $0{ }^{\circ} \mathrm{C}, 3 \mathrm{~h}, 47-91 \%$; (k) Perfluoro-1-butanesulfonyl fluoride (PBSF), $\mathrm{NEt}_{3} \cdot(\mathrm{HF})_{3}$, TEA, acetonitrole $(\mathrm{ACN})$, r.t., 6 h, 18-79\%; (1) $\mathrm{Pd}(\mathrm{OH})_{2} / \mathrm{C}, \mathrm{H}_{2}, \mathrm{MeOH} / \mathrm{DCM}(2: 1$, v/v), r.t., 10 h, $41-99 \%$.

alkynes of $\mathbf{1 a}-\mathbf{c}$ and $\mathbf{2 a}, \mathbf{2 b}$ were connected via coppermediated alkyne-alkyne cross coupling reaction to yield $3 \mathbf{a}-\mathbf{e}$ having C-16 to C-20 chain lengths. After the coupling step, the hydroxyl group of $3 \mathbf{a}-\mathbf{e}$ was mesylated to generate $4 \mathbf{a}-\mathbf{e}$. Then, PMB-protected ethyl 4-hydroxyacetoacetate was introduced into $4 \mathbf{a}-\mathbf{e}$ by using its doubly activated $\alpha$ carbon as a nucleophile to generate 5a-e. Hydrolysis and decarboxylation reaction sequentially proceeded under basic conditions to yield 6a-e. The desired carboxylic acid derivatives $7 \mathbf{a}-\mathbf{e}$ were generated via the deprotection of THP group and the subsequent oxidation of the resulting alcohols with Jones reagent.

Next, the azido group of $\alpha$-galactosylazidosphingoid $\mathbf{8}$, synthesized by the previously reported method, ${ }^{25}$ was converted to an amine 9 by Staudinger reduction and then coupled with $7 \mathbf{a}-\mathbf{e}$ under the EDC and DMAP condition to yield 10a-e. The PMB group at the terminal alcohol was selectively deprotected in 5\% TFA condition to yield $\alpha$ hydroxycarbonyl derivatives $11 \mathrm{a}-\mathbf{e}$. The conversion of alcohol to fluoride was achieved under the condition of PBSF/ $\mathrm{NEt}_{3}(\mathrm{HF})_{3} / \mathrm{NEt}_{3}$ in $\mathrm{ACN}$. This reaction condition, reported by Huffman, ${ }^{26}$ afforded a direct and convenient conversion from $\alpha$-hydroxycarbonyl to $\alpha$-fluorocarbonyl moiety. Finally, the desired $\alpha$-GalCer analogues F1-F5 were achieved via global deprotection of six benzyl groups in $12 \mathrm{a}-\mathbf{e}$ along with the full reduction of triple bonds simultaneously by palladiummediated catalytic hydrogenation.

Through this synthetic pathway, we were able to obtain the desired five $\alpha$-GalCer analogues (F1-F5) containing an $\alpha$ - fluorocarbonyl moiety at the terminal position of the acyl chain. It is worthy of mentioning that our synthetic pathway allows convenient adjustment of the length of acyl chains and introduces different functional groups at the terminus of the acyl chain. Thus, it could be applicable to the synthesis of the other lipid analogues. To investigate whether the designed ligands, F1-F5, can stimulate the cytokine release from iNKT cells, we measured the levels of cytokine induction in primary murine hepatic mononuclear cells (HMNCs) containing iNKT cells. It has been widely reported that iNKT cells produce various cytokines including IFN- $\gamma$ (the Th1-type cytokine) and IL-4 (the Th2-type cytokine) in response to the treatment of glycolipid ligands. ${ }^{3,27}$ Briefly, HMNCs were incubated with individual $\alpha$-GalCer analogues $(25 \mathrm{nM})$ for $72 \mathrm{~h}$, and the effects of these analogues on cytokine induction levels were detected by ELISA. ${ }^{28,29}$ Prototype $\alpha$-GalCer was used as a positive control. The bioassay results of each analogue were compared to that of the positive control, $\alpha$-GalCer, along with that of $\mathrm{OCH}$ (Figure 1a), known as the Th2-biasing ligand, ${ }^{30}$ for comparison.

We first examined the IL-2 level, and all of the newly designed analogues were as effective as $\alpha$-GalCer in promoting IL-2 production (Figure S1). IL-2 secretion is known to be dependent on the antigen-loaded CD1d. ${ }^{1,31}$ Therefore, we concluded that all of our analogues were accommodated at the binding pocket of CD1d in a proper orientation. Next, we measured the cellular level of IFN- $\gamma$ and IL-4 induction upon treatment with $\alpha$-GalCer, $\mathrm{OCH}$, and F1-F5. As shown in Figure $3 \mathrm{a}$, all of the new ligands showed higher selectivity 
a

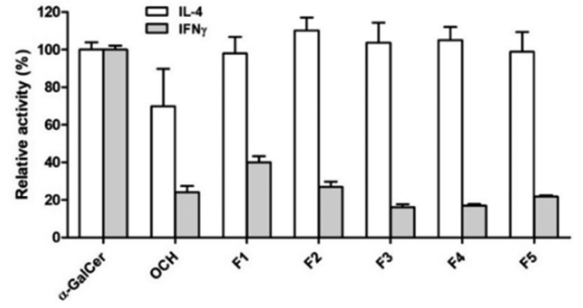

b

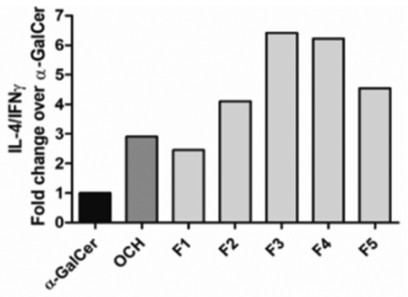

C

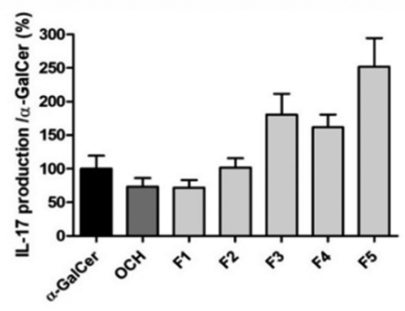

Figure 3. iNKT stimulatory activity of $\alpha$-GalCer analogues. (a) IFN- $\gamma$ and IL-4 secretion upon treatment of individual $\alpha$-GalCer analogues measured after $72 \mathrm{~h}$ in HMNC. (b) The relative ratio of IFN- $\gamma$ and IL-4 cytokine production of each analogue was compared with $\alpha$ GalCer. (c) IL-17 secretion from HMNCs upon treatment with individual $\alpha$-GalCer analogues after $72 \mathrm{~h}$.

toward IL-4 production compared to $\alpha$-GalCer. In the case of the known Th2-biasing ligand $\mathrm{OCH}$, it showed Th2 selective activity with decreased levels of both IL-4 and IFN- $\gamma$. Interestingly, the IL-4 induction levels were retained upon treatment with F1-F5, but cellular IFN- $\gamma$ levels were decreased. Particularly, F2-F5 exhibited higher selectivity for the induction of IL-4 over IFN- $\gamma$, compared with that of the known Th2-selective ligand $\mathrm{OCH}$ (Figure $3 b$ ).

In addition, we evaluated the cytokine induction level of IL17. F3-F5 showed the higher cytokine secretion of IL-17 compared with $\alpha$-GalCer (Figure 3c). Although little is known about how the interaction between CD1d and ligands affects the IL-17 induction, it was reported that both IFN- $\gamma$ and IL-4 cytokines suppressed IL-17 production. ${ }^{32,33}$ According to our observations, the secretion of IFN- $\gamma$ by F3, F4, and F5 was decreased, and this phenomenon may affect the IL-17 secretion level. To explain this outcome, follow-up research might be needed on how the CD1d-ligand interaction affects the secretion of IL-17. The $\alpha$-GalCer analogues F1-F5, having $\alpha$-fluorocarbonyl moiety at the terminal site of acyl chain, displayed highly Th2 biased activity.

To investigate the ligand-CD1d interaction, we tried to verify our design strategy using the covalent interaction between ligands and CD1d. We first incubated CD1d protein with each ligand in various reported and modified conditions, ${ }^{19,29,34-37}$ and the samples were denatured and analyzed by sodium dodecyl sulfate-polyacrylamide gel electrophoresis (SDS-PAGE) to observe the covalent adducts of CD1d-ligand. But Coomassie blue staining of the gel showed only the intact CD1d protein in all samples. We also performed matrix-assisted laser desorption/ionization time-of-flight (MALDI-TOF) mass spectrometry study of those incubated samples to check the existence of CD1d-ligand covalent conjugates. However, we were not able to detect any evidence of covalent bonds between CD1d cysteine and the $\alpha$ fluorocarbonyl moiety of ligands (Figure S2).

Thus, we contemplated the other possibility of the interaction between CD1d and $\alpha$-GalCer analogues; the $\alpha$ fluorocarbonyl moiety might serve as two hydrogen bonding acceptors (carbonyl oxygen and fluorine), which could induce the noncovalent hydrogen-bonding interaction with the residues at the binding pocket of CD1d. Based on the fact that the acyl chain of $\alpha$-GalCer is not a highly ordered structure, ${ }^{18}$ it is possible that the acyl chain of $\alpha$-GalCer analogues might get the stable conformation via hydrogenbonding interaction between a polar residue at the $\mathrm{A}^{\prime}$ pocket of CD1d and $\alpha$-fluorocarbonyl moiety of ligands. In fact, the hydrogen-bonding ability of Cys 12 at the $\mathrm{A}^{\prime}$ pocket of CD1d has already been proven in the previous report. They clearly demonstrated that Cys 12 has the hydrogen-bonding interaction with the carbonyl oxygen of palmitic acid in their X-ray crystal structure study. ${ }^{38}$ To identify the possible hydrogenbonding interactions at the binding pocket of CD1d, the binding modes of F3, F4, and F5 were simulated using the Discovery studio CDOCKER protocol. As shown in Figure S3, the sugar and sphingosine neck part have a relatively rigid conformation; therefore, we docked only the modified acyl part of designed ligands. The docking results are presented in Figure 4. The fully saturated original fatty acyl chain of $\alpha$ GalCer is located in a circle around the Cys12 in a

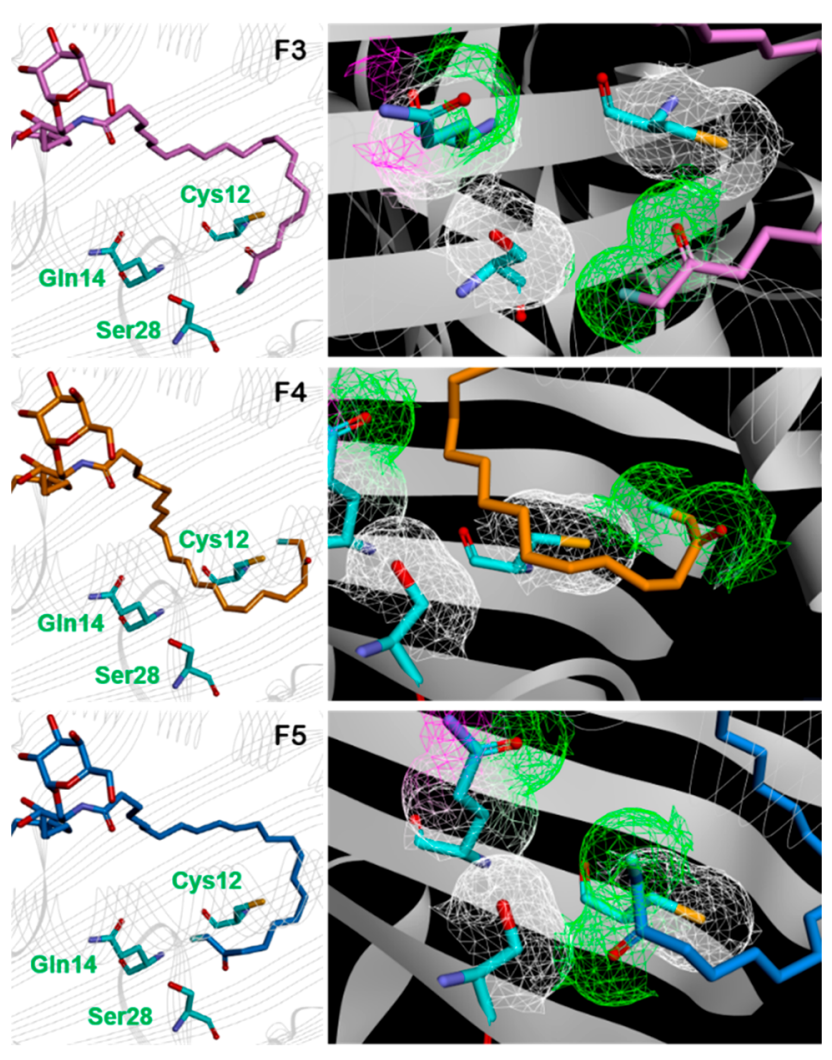

Figure 4. Molecular docking simulation of F3, F4, and F5 in mCD1d (PDB: 3G08). Key residues and $\alpha$-GalCer analogues are shown in stick model. The surfaces of potential hydrogen-bonding donor atoms and acceptor atoms were displayed as van der Waals radius as wire mesh with hydrogen bond donors in pink and hydrogen bond acceptors in green. 
counterclockwise way (Figure 1b). But the modified acyl chains, in our docking model, showed two different binding modes: clockwise conformation (F3 and F5) and counterclockwise conformation (F4). In the case of F3, the surface of the carbonyl oxygen of the $\alpha$-fluorocarbonyl moiety is in contact with the surface of the Cys12 thiol (Figure 4, first panel). This contact indicates the possibility of hydrogenbonding interaction between cysteine thiol and carbonyl oxygen. F4 also has an overlap with Cys12, but unlike the case of F3, the fluorine of F4 showed the contact with Cys 12 (Figure 4, second panel), which might be caused by the counterclockwise conformation surrounding Cys12. In the case of F5, though the acyl chain of F5 has the clockwise conformation like F3, carbonyl oxygen appears to have a hydrogen-bonding interaction with Ser28, instead of Cys12, since its acyl chain is longer (Figure 4, third panel). Interestingly, unlike the case of F3 and F4, F5 showed two possible binding modes and the clockwise conformation was slightly more stable than its counterclockwise mode according to docking scores (Figure S4).

To confirm the reliability of in silico docking studies, we conducted the docking analysis using a reported $\alpha$-GalCer derivative containing an amide group in the acyl chain, $1 \boldsymbol{d}$ (Figure S5), which was reported to have hydrogen-bonding interactions with Ser28 and Gln 14 by the Fujimoto group (Figure 1a). ${ }^{18}$ When we applied the same docking process to this ligand $1 d$, the surface of the carbonyl oxygen of the amide was overlapped with the surface of Ser28 as expected (Figure S5). Thus, this in silico analysis suggested that the hydrogen bonding of these polar residues at the $\mathrm{A}^{\prime}$ pocket of CD1d would contribute to our ligand-CD1d interaction. Assuming that our newly designed $\alpha$-GalCer analogues might have hydrogen-bonding interactions with CD1d, the tendency of cytokine profiling results considerably matched with the previously reported hydrophilic region targeting Th2-biasing ligands. ${ }^{19}$

In this study, our initial goal was the development of covalent $\alpha$-GalCer ligands containing an $\alpha$-fluorocarbonyl moiety at the terminus of the acyl chains to enhance the occupation time at the binding pocket of CD1d for selective cytokine inductions. Therefore, we developed a new synthetic route to access $\alpha$-GalCer analogues containing long acyl chains with an $\alpha$-fluorocarbonyl moiety at the terminus. By utilizing an asymmetric alkyne-alkyne coupling strategy, we could successfully introduce the $\alpha$-fluorocarbonyl moiety with the freely adjustable chain length. The newly synthesized five $\alpha$ GalCer analogues (F1-F5) were then subject to ELISA-based biological evaluation to identify the selective inducer of various cytokines. Even though we developed highly Th2-biased selective ligands in iNKT cells, we were not able to identify the covalent adducts of CD1d with our $\alpha$-GalCer analogues. Instead of covalent adducts, we hypothesized the potential hydrogen-bonding interaction of the $\alpha$-fluorocarbonyl moiety with polar residues at the $\mathrm{A}^{\prime}$ pocket of $\mathrm{CD} 1 \mathrm{~d}$, which was visualized by in silico docking analysis. These Th2-selective analogues could be used as chemical tools to investigate CD1dglycolipid-NKT ternary interaction related to cytokine-biasing mechanisms. In addition, our rational design strategy could contribute to the development of other glycolipid-based CD1d ligands.

\section{ASSOCIATED CONTENT}

\section{Supporting Information}

The Supporting Information is available free of charge on the ACS Publications website at DOI: 10.1021/acsmedchemlett.9b00026.

Additional supporting figures, detailed synthetic procedure, spectroscopic data, and full characterizations of all new compounds, and procedures for biological experiment including ELISA assay. (PDF)

\section{AUTHOR INFORMATION}

\section{Corresponding Author}

*Phone: +82-2-880-9090. Fax: +82-2-884-4025. E-mail: sbpark@snu.ac.kr.

ORCID $\odot$

Seung Bum Park: 0000-0003-1753-1433

\section{Present Address}

"(H.S.) Memory Division, Samsung Electronics Co., Ltd., Hwaseong-si, Gyeonggi-do, Korea.

\section{Author Contributions}

${ }^{\S}$ H.K. and H.S. contributed equally. H.K. and H.S. prepared the manuscript, performed the in silico docking study, and synthesized all compounds used in this study. J.-G.P. and D.S.L. performed biological evaluations. S.B.P. directed the study in all aspects of the experimental design, data analysis, and manuscript preparation. All authors critically reviewed the text and figures.

\section{Funding}

This work was partly supported by the Creative Research Initiative Grant (2014R1A3A2030423), the Bio \& Medical Technology Development Program (2012M3A9C4048780), and the Basic Research Laboratory (2017R1A4A1015745) through the National Research Foundation of Korea (NRF) funded by the Korean Government (Ministry of Science \& ICT). H.K., H.S., and J.-G.P. are grateful for the fellowship by the BK21 Plus Program.

\section{Notes}

The authors declare no competing financial interest.

\section{ABBREVIATIONS}

iNKT, invariant natural killer $\mathrm{T}$; Th1, T helper 1; Th2, T helper 2; Th17, T helper 17; IFN- $\gamma$, interferon- $\gamma$; TNF- $\alpha$, tumor necrosis factor- $\alpha$; IL, interleukin; mCD1d, mouse CD1d; ELISA, enzyme-linked immunosorbent assay

\section{REFERENCES}

(1) Bendelac, A.; Savage, P. B.; Teyton, L. The Biology of NKT Cells. Annu. Rev. Immunol. 2007, 25, 297-336.

(2) Van Kaer, L.; Wu, L.; Joyce, S. Mechanisms and Consequences of Antigen Presentation by CD1. Trends Immunol. 2016, 37, 738754

(3) Rossjohn, J.; Pellicci, D. G.; Patel, O.; Gapin, L.; Godfrey, D. I. Recognition of CD1d-Restricted Antigens by Natural Killer T Cells. Nat. Rev. Immunol. 2012, 12, 845.

(4) Laurent, X.; Bertin, B.; Renault, N.; Farce, A.; Speca, S.; Milhomme, O.; Millet, R.; Desreumaux, P.; Hénon, E.; Chavatte, P. Switching Invariant Natural Killer T (iNKT) Cell Response from Anticancerous to Anti-Inflammatory Effect: Molecular Bases. J. Med. Chem. 2014, 57, 5489-5508.

(5) Anderson, B.; Teyton, L.; Bendelac, A.; Savage, P. Stimulation of Natural Killer T Cells by Glycolipids. Molecules 2013, 18, 15662. 
(6) Fujio, M.; Wu, D. G.; Garcia-Navarro, R.; Ho, D. D.; Tsuji, M.; Wong, C. H. Structure-Based Discovery of Glycolipids for CD1dMediated NKT Cell Activation: Tuning the Adjuvant versus Immunosuppression Activity. J. Am. Chem. Soc. 2006, 128, 9022.

(7) Lee, T.; Cho, M.; Ko, S. Y.; Youn, H. J.; Baek, D. J.; Cho, W. J.; Kang, C. Y.; Kim, S. Synthesis and Evaluation of 1,2,3-Triazole Containing Analogues of the Immunostimulant $\alpha$-GalCer. J. Med. Chem. 2007, 50, 585.

(8) Henon, E.; Dauchez, M.; Haudrechy, A.; Banchet, A. Molecular Dynamics Simulation Study on the Interaction of KRN 7000 and Three Analogues with Human CD1d. Tetrahedron 2008, 64, 9480.

(9) Hossain, M. I.; Hanashima, S.; Nomura, T.; Lethu, S.; Tsuchikawa, H.; Murata, M.; Kusaka, H.; Kita, S.; Maenaka, K. Synthesis and Th1-Immunostimulatory Activity of $\alpha$-Galactosylceramide Analogues Bearing a Halogen-Containing or SeleniumContaining Acyl Chain. Bioorg. Med. Chem. 2016, 24, 3687-3695.

(10) Im, J. S.; Arora, P.; Bricard, G.; Molano, A.; Venkataswamy, M. M.; Baine, I.; Jerud, E. S.; Goldberg, M. F.; Baena, A.; Yu, K. O. A.; Ndonye, R. M.; Howell, A. R.; Yuan, W.; Cresswell, P.; Chang, Y.-t.; Illarionov, P. A.; Besra, G. S.; Porcelli, S. A. Kinetics and Cellular Site of Glycolipid Loading Control the Outcome of Natural Killer T Cell Activation. Immunity 2009, 30, 888-898.

(11) Arora, P.; Venkataswamy, M. M.; Baena, A.; Bricard, G.; Li, Q.; Veerapen, N.; Ndonye, R.; Park, J. J.; Lee, J. H.; Seo, K.-C.; Howell, A. R.; Chang, Y.-T.; Illarionov, P. A.; Besra, G. S.; Chung, S.-K.; Porcelli, S. A. A Rapid Fluorescence-Based Assay for Classification of iNKT Cell Activating Glycolipids. J. Am. Chem. Soc. 2011, 133, 5198-5201.

(12) Wun, K. S.; Cameron, G.; Patel, O.; Pang, S. S.; Pellicci, D. G.; Sullivan, L. C.; Keshipeddy, S.; Young, M. H.; Uldrich, A. P.; Thakur, M. S.; Richardson, S. K.; Howell, A. R.; Illarionov, P. A.; Brooks, A. G.; Besra, G. S.; McCluskey, J.; Gapin, L.; Porcelli, S. A.; Godfrey, D. I.; Rossjohn, J. A Molecular Basis for the Exquisite CD1d-Restricted Antigen Specificity and Functional Responses of Natural Killer T Cells. Immunity 2011, 34, 327-339.

(13) Pellicci, D. G.; Patel, O.; Kjer-Nielsen, L.; Pang, S. S.; Sullivan, L. C.; Kyparissoudis, K.; Brooks, A. G.; Reid, H. H.; Gras, S.; Lucet, I. S.; Koh, R.; Smyth, M. J.; Mallevaey, T.; Matsuda, J. L.; Gapin, L.; McCluskey, J.; Godfrey, D. I.; Rossjohn, J. Differential Recognition of CD1d- $\alpha$-Galactosyl Ceramide by the V $\beta 8.2$ and V $\beta 7$ Semi-invariant NKT T Cell Receptors. Immunity 2009, 31, 47-59.

(14) Patel, O.; Pellicci, D. G.; Uldrich, A. P.; Sullivan, L. C.; Bhati, M.; McKnight, M.; Richardson, S. K.; Howell, A. R.; Mallevaey, T.; Zhang, J.; Bedel, R.; Besra, G. S.; Brooks, A. G.; Kjer-Nielsen, L.; McCluskey, J.; Porcelli, S. A.; Gapin, L.; Rossjohn, J.; Godfrey, D. I. V $\beta 2$ Natural Killer T Cell Antigen Receptor-Mediated Recognition of CD1d-glycolipid Antigen. Proc. Natl. Acad. Sci. U. S. A. 2011, 108, 19007-19012.

(15) Vartabedian, V. F.; Savage, P. B.; Teyton, L. The Processing and Presentation of Lipids and Glycolipids to the Immune System. Immunol. Rev. 2016, 272, 109-119.

(16) Sullivan, B. A.; Nagarajan, N. A.; Wingender, G.; Wang, J.; Scott, I.; Tsuji, M.; Franck, R. W.; Porcelli, S. A.; Zajonc, D. M.; Kronenberg, M. Mechanisms for Glycolipid Antigen-Driven Cytokine Polarization by V $\alpha 14$ iNKT Cells. J. Immunol. 2010, 184, 141-153.

(17) Lim, C.; Kim, J. H.; Baek, D. J.; Lee, J.-Y.; Cho, M.; Lee, Y.-S.; Kang, C.-Y.; Chung, D. H.; Cho, W.-J.; Kim, S. Design and Evaluation of $\omega$-Hydroxy Fatty Acids Containing $\alpha$-GalCer Analogues for CD1dMediated NKT Cell Activation. ACS Med. Chem. Lett. 2014, 5, 331335.

(18) Inuki, S.; Aiba, T.; Hirata, N.; Ichihara, O.; Yoshidome, D.; Kita, S.; Maenaka, K.; Fukase, K.; Fujimoto, Y. Isolated Polar Amino Acid Residues Modulate Lipid Binding in the Large Hydrophobic Cavity of CD1d. ACS Chem. Biol. 2016, 11, 3132-3139.

(19) Inuki, S.; Kashiwabara, E.; Hirata, N.; Kishi, J.; Nabika, E.; Fujimoto, Y. Potent Th2 Cytokine Bias of Natural Killer T Cell by CD1d Glycolipid Ligands: Anchoring Effect of Polar Groups in the Lipid Component. Angew. Chem. 2018, 130, 9803-9807.
(20) Powers, J. C.; Asgian, J. L.; Ekici, Ö. D.; James, K. E. Irreversible Inhibitors of Serine, Cysteine, and Threonine Proteases. Chem. Rev. 2002, 102, 4639-4750.

(21) Veerapen, N.; Kharkwal, S. S.; Jervis, P.; Bhowruth, V.; Besra, A. K.; North, S. J.; Haslam, S. M.; Dell, A.; Hobrath, J.; Quaid, P. J.; Moynihan, P. J.; Cox, L. R.; Kharkwal, H.; Zauderer, M.; Besra, G. S.; Porcelli, S. A. Photoactivable Glycolipid Antigens Generate Stable Conjugates with CD1d for Invariant Natural Killer T Cell Activation. Bioconjugate Chem. 2018, 29, 3161-3173.

(22) Cohen, M. S.; Zhang, C.; Shokat, K. M.; Taunton, J. Structural Bioinformatics-Based Design of Selective, Irreversible Kinase Inhibitors. Science 2005, 308, 1318-1321.

(23) Chatterjee, S.; Ator, M. A.; Bozyczko-Coyne, D.; Josef, K.; Wells, G.; Tripathy, R.; Iqbal, M.; Bihovsky, R.; Senadhi, S. E.; Mallya, S.; O’Kane, T. M.; McKenna, B. A.; Siman, R.; Mallamo, J. P. Synthesis and Biological Activity of a Series of Potent Fluoromethyl Ketone Inhibitors of Recombinant Human Calpain I. J. Med. Chem. 1997, 40, 3820-3828.

(24) Hwang, Y.; Thompson, P. R.; Wang, L.; Jiang, L.; Kelleher, N. L.; Cole, P. A. A Selective Chemical Probe for Coenzyme A-Requiring Enzymes. Angew. Chem., Int. Ed. 2007, 46, 7621-7624.

(25) Shiozaki, M.; Tashiro, T.; Koshino, H.; Shigeura, T.; Watarai, H.; Taniguchi, M.; Mori, K. Synthesis and Biological Activity of Hydroxylated Analogues of KRN7000 ( $\alpha$-Galactosylceramide). Carbohydr. Res. 2013, 370, 46-66.

(26) Yin, J.; Zarkowsky, D. S.; Thomas, D. W.; Zhao, M. M.; Huffman, M. A. Direct and Convenient Conversion of Alcohols to Fluorides. Org. Lett. 2004, 6, 1465-1468.

(27) Matsuda, J. L.; Mallevaey, T.; Scott-Browne, J.; Gapin, L. CD1d-restricted iNKT cells, the 'Swiss-Army knife' of the immune system. Curr. Opin. Immunol. 2008, 20, 358-368.

(28) Kim, Y.; Kim, J.; Oh, K.; Lee, D.-S.; Park, S. B. Heteroaromatic Moieties in the Sphingosine Backbone of $\alpha$-Galactosylceramides for Noncovalent Interactions with CD1d. ACS Med. Chem. Lett. 2012, 3, $151-154$.

(29) Kim, Y.; Oh, K.; Song, H.; Lee, D.-S.; Park, S. B. Synthesis and Biological Evaluation of $\alpha$-Galactosylceramide Analogues with Heteroaromatic Rings and Varying Positions of a Phenyl Group in the Sphingosine Backbone. J. Med. Chem. 2013, 56, 7100-7109.

(30) Miyamoto, K.; Miyake, S.; Yamamura, T. A. Synthetic GlycoLipid Prevents Autoimmune Encephalomyelitis by Inducing TH2 Bias of Natural Killer T Cells. Nature 2001, 413, 531.

(31) Prigozy, T. I.; Naidenko, O.; Qasba, P.; Elewaut, D.; Brossay, L.; Khurana, A.; Natori, T.; Koezuka, Y.; Kulkarni, A.; Kronenberg, M. Glycolipid Antigen Processing for Presentation by CD1d Molecules. Science 2001, 291, 664-667.

(32) Park, H.; Li, Z.; Yang, X. O.; Chang, S. H.; Nurieva, R.; Wang, Y.-H.; Wang, Y.; Hood, L.; Zhu, Z.; Tian, Q.; Dong, C. A Distinct Lineage of CD4 $\mathrm{T}$ Cells Regulates Tissue Inflammation by Producing Interleukin 17. Nat. Immunol. 2005, 6, 1133.

(33) Michel, M.-L.; Keller, A. C.; Paget, C.; Fujio, M.; Trottein, F.; Savage, P. B.; Wong, C.-H.; Schneider, E.; Dy, M.; Leite-de-Moraes, M. C. Identification of an IL-17-Producing NK1.1neg iNKT Cell Population Involved in Airway Neutrophilia. J. Exp. Med. 2007, 204, 995-1001.

(34) Birkholz, A. M.; Girardi, E.; Wingender, G.; Khurana, A.; Wang, J.; Zhao, M.; Zahner, S.; Illarionov, P. A.; Wen, X.; Li, M.; Yuan, W.; Porcelli, S. A.; Besra, G. S.; Zajonc, D. M.; Kronenberg, M. A Novel Glycolipid Antigen for NKT Cells That Preferentially Induces IFN- $\gamma$ Production. J. Immunol. 2015, 195, 924-933.

(35) López-Sagaseta, J.; Kung, J. E.; Savage, P. B.; Gumperz, J.; Adams, E. J. The Molecular Basis for Recognition of CD1d/ $\alpha$ Galactosylceramide by a Human Non-V $\alpha 24$ T Cell Receptor. PLoS Biol. 2012, 10, No. e1001412.

(36) Chennamadhavuni, D.; Saavedra-Avila, N. A.; Carreño, L. J.; Guberman-Pfeffer, M. J.; Arora, P.; Yongqing, T.; Pryce, R.; Koay, H.F.; Godfrey, D. I.; Keshipeddy, S.; Richardson, S. K.; Sundararaj, S.; Lo, J. H.; Wen, X.; Gascón, J. A.; Yuan, W.; Rossjohn, J.; Le Nours, J.; Porcelli, S. A.; Howell, A. R. Dual Modifications of $\alpha$-Galactosylcer- 
amide Synergize to Promote Activation of Human Invariant Natural Killer T Cells and Stimulate Anti-Tumor Immunity. Cell Chem. Biol. 2018, 25, 571-584.e8.

(37) Bernardim, B.; Cal, P. M. S. D.; Matos, M. J.; Oliveira, B. L.; Martínez-Sáez, N.; Albuquerque, I. S.; Perkins, E.; Corzana, F.; Burtoloso, A. C. B.; Jiménez-Osés, G.; Bernardes, G. J. L. Stoichiometric and Irreversible Cysteine-Selective Protein Modification Using Carbonylacrylic Reagents. Nat. Commun. 2016, 7, 13128.

(38) Wu, D.; Zajonc, D. M.; Fujio, M.; Sullivan, B. A.; Kinjo, Y.; Kronenberg, M.; Wilson, I. A.; Wong, C.-H. Design of Natural Killer

$T$ Cell Activators: Structure and Function of a Microbial Glycosphingolipid Bound to Mouse CD1d. Proc. Natl. Acad. Sci. U. S. A. 2006, 103, 3972-3977. 